\title{
Influence of deformation temperature on structural variation and shape-memory effect of a thermoplastic semi-crystalline multiblock copolymer
}

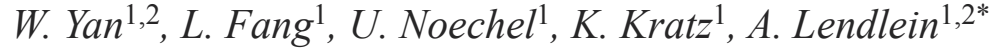 \\ ${ }^{1}$ Institute of Biomaterial Science and Berlin-Brandenburg Center for Regenerative Therapies, Helmholtz Zentrum \\ Geesthacht, Kantstr. 55, 14513 Teltow, Germany \\ ${ }^{2}$ Institute of Chemistry, University of Potsdam, 14476 Potsdam, Germany
}

Received 17 November 2014; accepted in revised form 31 January 2015

\begin{abstract}
A multiblock copolymer termed as PCL-PIBMD, consisting of crystallizable poly(E-caprolactone) (PCL) segments and crystallizable poly(3S-isobutyl-morpholine-2,5-dione) (PIBMD) segments, has been reported as a material showing a thermally-induced shape-memory effect. While PIBMD crystalline domains act as netpoints to determine the permanent shape, both PCL crystalline domains and PIBMD amorphous domains, which have similar transition temperatures $\left(T_{\text {trans }}\right)$ can act as switching domains. In this work, the influence of the deformation temperature $\left(T_{\text {deform }}=50\right.$ or $\left.20^{\circ} \mathrm{C}\right)$, which was above or below $T_{\text {trans, }}$, on the structural changes of PCL-PIBMD during uniaxial deformation and the shapememory properties were investigated. Furthermore, the relative contribution of crystalline PCL and PIBMD amorphous phases to the fixation of the temporary shape were distinguished by a toluene vapor treatment approach. The results indicated that at $50^{\circ} \mathrm{C}$, both PCL and PIBMD amorphous phases can be orientated during deformation, resulting in thermallyinduced crystals of PCL domains and joint contribution to the switching domains. In contrast at $20^{\circ} \mathrm{C}$, the temporary shape was mainly fixed by PCL crystals generated via strain-induced crystallization.
\end{abstract}

Keywords: biodegradable polymers, shape-memory polymer, multiblock copolymer, polydepsipeptide

\section{Introduction}

Shape-memory polymers (SMPs) can be deformed from their permanent shape and temporarily fixed in a second shape. The original shape can be recovered by application of suitable external stimulus, such as e.g. heat [1-6]. Suitable molecular architectures consisting of netpoints determining the permanent shape and molecular switches fixing the temporary shape are required to enable a shape-memory effect (SME) in polymers [1-3]. Multiblock copolymers (MBCs) consisting of at least two segregated domains, thus, are considered as a versatile molecular architecture in creating SMPs [1, 2, 6-8]. Recently, a novel class of MBCs composed of crys- tallizable poly( $\varepsilon$-caprolactone) (PCL) segments and crystallizable poly(3S-isobutyl-morpholin-2,5-dione) (PIBMD) segments was introduced and termed as PCL-PIBMD. It has been reported that excellent SME can be found in PCL-PIBMD with $50 \mathrm{wt} \%$ PIBMD segments [6-8]. In addition, while PIBMD crystals with a high melting temperature $\left(T_{\mathrm{m}}\right)$ of $170^{\circ} \mathrm{C}$ act as permanent physical netpoints, the melting temperature of PCL crystallites $\left(T_{\mathrm{m}, \mathrm{PCL}} \approx 38^{\circ} \mathrm{C}\right)$ is close to the glass transition temperature of PIBMD $\left(T_{\mathrm{g}, \text { PIBMD }} \approx 42^{\circ} \mathrm{C}\right)$ domains [6-8]. Therefore, both the PCL crystalline phase and the PIBMD amorphous phase form the switching domains.

\footnotetext{
$\overline{{ }^{*} \text { Corresponding author, e-mail: andreas.lendlein@hzg.de }}$ (C) BME-PT
} 
The deformation temperature $\left(T_{\text {deform }}\right)$ has significant effects on deformation behaviors of semi-crystalline polymers on the microscopic and macroscopic scale $[9,10]$, with structural variations during the deformation playing a dominant role in determining their mechanical properties [11, 12]. It also has been reported that $T_{\text {deform }}$ can affect the SME of semicrystalline MBCs, i.e., if the samples are deformed at a temperature lower than the thermal transition temperature ( $\left.T_{\text {trans }}\right)$ of switching domains, reduction in fixity ratio $\left(R_{\mathrm{f}}\right)$ and switching temperature $\left(T_{\mathrm{sw}}\right)$ can be observed as well as a higher maximum stress $\left(\sigma_{\mathrm{m}}\right)$ is required [13-14]. Therefore, it is necessary to explore the mechanisms of structural evolutions in semi-crystalline MBCs deformed at different temperatures to gain further insights into structure/ property-function relations for mechanical properties and the shape-memory capability. As far as PCL-PIBMD is concerned, the PIBMD amorphous phase in PCL-PIBMD will be in the rubbery state if PCL-PIBMD is deformed at a temperature higher than $T_{\mathrm{g}, \mathrm{PIBMD}}$. Its structural response during deformation should be different from the case in which the PIBMD amorphous phase is in the glassy state if PCL-PIBMD is deformed at a temperature lower than $T_{\mathrm{g}, \text { PIBMD }}$. Such difference is anticipated to cause distinct SMEs as well as the variation in the relative contributions of PIBMD amorphous phase and PCL crystals to switching domains.

In this work, the structural variations of PCL-PIBMD (with a $50 \mathrm{wt} \%$ PIBMD) deformed to a strain of $200 \%$ at $T_{\text {deform }}=20$ or $50^{\circ} \mathrm{C}$, which are below and

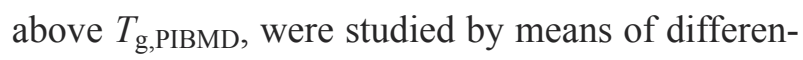
tial scanning calorimetry (DSC), atomic force microscopy (AFM), wide-angle X-ray scattering (WAXS) and small-angle X-ray scattering (SAXS). The corresponding shape-memory properties were evaluated via cyclic, thermomechanical tensile testing. Furthermore, a new method of toluene vapor treatment was applied in order to separate the relative contributions of PCL crystalline phase and PIBMD amorphous phase to switching domains.

\section{Experimental}

\subsection{Materials}

PCL-diol with number average molecular weight $\left(M_{\mathrm{n}}\right)$ of $2700 \mathrm{~g} \cdot \mathrm{mol}^{-1}$ and a polydispersity of 1.7 was obtained from Solvay Caprolactones (Warrington, UK). PIBMD-diol with a number averaged molecular weight $M_{\mathrm{n}}=9300 \mathrm{~g} \cdot \mathrm{mol}^{-1}$ was prepared by ring open polymerization of morpholine-2,5-diones in the melt using $\mathrm{Sn}(\mathrm{Oct})_{2}$ as catalyst according to Ref. [6]. Other reagents, such as 2,2(4),4-trimethyl-hexamethylene diisocyanate, (TMDI, Aldrich, Taufkirchen, Germany), amino acids (Aldrich, Taufkirchen, Germany) and solvents (Merck, Darmstadt, Germany) were of commercial grade and used without further purification.

As reported in Ref. [6], for synthesis of PCL-PIBMD containing $50 \mathrm{wt} \%$ PIBMD, $24.0 \mathrm{~g}$ PCL-diol was reacted with $22.5 \mathrm{~g}$ PIBMD-diol and $3.32 \mathrm{~mL}$ TMDI in $110 \mathrm{~mL} \mathrm{~N}$-methylpyrrolidone at $80^{\circ} \mathrm{C}$ for $24 \mathrm{~h}$ by using $43 \mu \mathrm{L}$ dibutyltin dilaurate as catalyst. Subsequently, another $100 \mu \mathrm{L}$ TMDI was added to the mixture to react for another $24 \mathrm{~h}$. After reaction, the mixture was diluted with $200 \mathrm{~mL}$ 1,2-dichloroethane and precipitated in a tenfold excess of diethyl ether. The product was collected by suction filtration and dried in a vacuum at room temperature for $24 \mathrm{~h}$. The $M_{\mathrm{n}}$ of the PCL-PIBMD product was $53000 \mathrm{~g} \cdot \mathrm{mol}^{-1}$ with polydispersity of 2.0 , determined by gel permeation chromatography (GPC).

\subsection{Film preparation}

PCL-PIBMD (2.28 g) was dissolved in chloroform $(50 \mathrm{~mL})$ overnight at ambient temperature. The solution casting was carried out in glass petri dishes (diameter $=80 \mathrm{~mm}$, Duran Group, Wertheim, Germany) with subsequent evaporation of chloroform for 5 days. The resulting film thickness was $270 \pm 30 \mu \mathrm{m}$, measured using a thickness gauge (Hans Schmidt, Waldkraiburg, Germany).

\subsection{Characterization methods}

\subsubsection{Gel permeation chromatography (GPC)}

Multidetector GPC measurements were performed using chloroform as eluent with a flow rate of $1 \mathrm{~mL} \cdot \mathrm{min}^{-1}$ and $0.2 \mathrm{wt} \%$ toluene as internal standard at $35^{\circ} \mathrm{C}$. The system was equipped with a precolumn, two $300 \mathrm{~mm} \times 8.0 \mathrm{~mm}$ linear $\mathrm{M}$ columns (Polymer Standards Service GmbH, (PSS) Mainz, Germany) an isocratic pump 2080 and an automatic injector AS 2050 (both Jasco, Tokyo, Japan). Three detectors were used: a UV detector UV-1575 (Jasco, $275 \mathrm{~nm}$ ): a RI detector Shodex RI-101 (Showa Denko, Japan) and the viscometer SEC-3010 (WGE, Dr. Bures, Dallgow, Germany) which were combined by a split. The molecular weights were determined using a universal calibration with polystyrene standards with $M_{\mathrm{n}}$ between $580 \mathrm{~g} \cdot \mathrm{mol}^{-1}$ and 
$975000 \mathrm{~g} \cdot \mathrm{mol}^{-1}(\mathrm{PSS})$ and with the help of the SEC software WINGPC Unity (PSS).

\subsubsection{Atomic force microscopy (AFM)}

The morphologies of solution cast films before and after deformation at different $T_{\text {deform }}$ s were investigated by AFM (Multimode with NanoScope V Controller, Veeco Instruments Inc.) with a temperature controller (Veeco Thermal Application Controller). The typical scan rate was $0.8-1.0 \mathrm{~Hz}$. The silicon cantilevers (OLYMPUS OMCL AC200TS-R3), having a driving frequency of around $150 \mathrm{KHz}$ and a spring constant of $9 \mathrm{~N} \cdot \mathrm{m}^{-1}$, were used for measurements. The tip has a radius of $7 \mathrm{~nm}$ and its back and side angles are $35^{\circ}$ and $18^{\circ}$, respectively.

\subsubsection{Differential scanning calorimetry (DSC)}

DSC experiments were conducted on a Netzsch DSC 204 Phoenix (Selb, Germany) at a heating rate of $10^{\circ} \mathrm{C} \cdot \mathrm{min}^{-1}$ in sealed aluminum pans. The polymer samples were cooled down from room temperature to $0^{\circ} \mathrm{C}$ before they were heated to $200^{\circ} \mathrm{C}$, while the $T_{\mathrm{m}}$ and related melting enthalpies $(\Delta H)$ were determined from DSC curves. A non-deformed PCLPIBMD sample was measured after being preconditioned by annealing at $75^{\circ} \mathrm{C}$ for $10 \mathrm{~min}$, then cooling down to $50^{\circ} \mathrm{C}$ and keeping for $10 \mathrm{~min}$ at $T_{\text {deform }}$, and afterwards cooling to $0^{\circ} \mathrm{C}$ with a cooling rate of $5^{\circ} \mathrm{C} \cdot \mathrm{min}^{-1}$ by using DSC to simulate the main thermal treatment applied during programming. The deformed samples were prepared as described in the following section 2.3.4.

\subsubsection{Cyclic, thermomechanical tensile tests}

Cyclic, thermomechanical, tensile tests were performed on a tensile tester (Zwick Z1.0, Ulm, Germany) equipped with a thermo chamber and a temperature controller (Eurotherm Regler, Limburg, Germany). Each cycle consisted of a shape-memory creation procedure (SMCP) and recovery modules, which can be performed under two different conditions: stress-free or constant-strain. The cycles were repeated three times per test.

Programming (SMCP) was performed using test specimens which were cut from the solution cast films according to the type DIN EN ISO 527-2/1BB (length $=20 \mathrm{~mm}$, width $=2 \mathrm{~mm}$ ). The specimen was heated up from room temperature to the upper working temperature $\left(T_{\text {high }}=75^{\circ} \mathrm{C}\right)$. After $10 \mathrm{~min}$, the temperature was reduced to $T_{\text {deform }}=50$ or $20^{\circ} \mathrm{C}$ at $5^{\circ} \mathrm{C} \cdot \mathrm{min}^{-1}$. After another $5 \mathrm{~min}$, the specimen was deformed to the strain of $\varepsilon_{\mathrm{m}}=200 \%$ at a deformation speed of $1 \mathrm{~mm} \cdot \mathrm{min}^{-1}$. Subsequently, the deformed specimen was kept at $T_{\text {deform }}$ for 5 min to allow relaxation. Then, the specimen was cooled down to lower temperature $\left(T_{\text {low }}=0^{\circ} \mathrm{C}\right)$ under constant-strain condition and equilibrated for $10 \mathrm{~min}$. Finally, the stress was removed and the temporary fixed elongation temporary strain $\left(\varepsilon_{\mathrm{u}}\right)$ was determined.

Recovery under stress-free condition was induced by heating the programmed sample from 0 to $75^{\circ} \mathrm{C}$ at $2^{\circ} \mathrm{C} \cdot \mathrm{min}^{-1}$ under stress-free condition. The switching temperature $\left(T_{\mathrm{sw}}\right)$ and recovery strain $\left(\varepsilon_{\mathrm{p}}\right)$ were determined.

Recovery under constant-strain condition was carried out after completion of the programming module by increasing the temperature from 0 to $75^{\circ} \mathrm{C}$ at $2^{\circ} \mathrm{C} \cdot \mathrm{min}^{-1} . \sigma_{\max }$ and its corresponding temperature $\left(T_{\sigma, \max }\right)$ were determined at the maximum value of $\sigma$ in the stress-temperature curve. The stress was completely released after reaching $T_{\text {high }}$ to allow the sample recovery. The characteristics for quantification of SME, $R_{\mathrm{f}}$ and shape recovery ratio $\left(R_{\mathrm{r}}\right)$, can be calculated by Equations (1) and (2) [1]:

$$
\begin{aligned}
& R_{\mathrm{f}}=\frac{\varepsilon_{\mathrm{u}}(N)}{\varepsilon_{\mathrm{m}}} \\
& R_{\mathrm{r}}=\frac{\varepsilon_{\mathrm{m}}-\varepsilon_{\mathrm{p}}(N)}{\varepsilon_{\mathrm{m}}-\varepsilon_{\mathrm{p}}(N-1)}
\end{aligned}
$$

where $N$ is the present $N^{\text {th }}$ cycle of cyclic test.

\subsubsection{Wide-angle $X$-ray scattering (WAXS)}

WAXS measurements were performed on the Bruker D8 Discover X-ray diffraction system with a twodimensional detector from Bruker AXS (Karlsruhe, Germany). The X-ray generator was operated at $40 \mathrm{kV}$ and $40 \mathrm{~mA}$ on a copper-anode. The collimator was chosen $0.8 \mathrm{~mm}$ (beam size). The two-dimensional detector (Hi-Star) was operated in $1024 \times$ 1024 pixel mode. The distance sample-detector was $150 \mathrm{~mm}$ and the wavelength $\lambda=0.15418 \mathrm{~nm}$. The detector was positioned at an angular position $2 \theta=$ $25^{\circ}$ in order to cover an angular range from $2 \theta=7.2$ to $43.5^{\circ}$. Exposure time was $120 \mathrm{~s}$ per scattering pattern. The raw patterns (two-dimensional) were all isotropic, thus a one-dimensional curve contains the same information as the 2D-pattern. Then an integration over an angle chi $\chi=120^{\circ}$ and the whole $2 \theta$ range was performed in order to obtain $1 \mathrm{D}$-scatter- 
ing curves using 5-point normalized binning. Non valid data points outward of the detector were not considered for integration. The scattering curves of semi-crystalline samples were decomposed into individual peaks, belonging either to the amorphous or the crystalline phase with the Bruker-software TOPAS $^{\circledR}$. A big amorphous bump was always present at $2 \theta=20^{\circ}$, crystalline peaks were found at various positions. The peaks of the two phases (amorphous and crystalline) were fitted with Pearson VII functions [15]. The relation of the peak position and breadth (FWHM) with the crystal size $\left(l_{\mathrm{c}}\right)$ is given by the Sherrer equation (Equation (3), parameter $k=$ $0.9)[15]$ :

$l_{\mathrm{c}}=\frac{k \cdot \lambda}{B \cdot \cos \theta}$

where $B=\mathrm{FWHM}$ (in radians); $\theta=$ half scattering angle; $\lambda=$ wavelength of $X$-rays.

A custom built tensile device was used for uniaxial deformation using type ISO 527-2/1BB dumbbell test bars $(20 \times 2 \times 1 \mathrm{~mm})$ at a cross-head speed of $1 \mathrm{~mm} \cdot \mathrm{min}^{-1}$. Heating was provided by a heating gun (heating rate $\sim 10^{\circ} \mathrm{C} \cdot \mathrm{min}^{-1}$, non-linear), whereby cooling was enabled by a cooled Nitrogen flux (Cooling rate $\sim 10^{\circ} \mathrm{C} \cdot \mathrm{min}^{-1}$, non-linear). The temperature was monitored by a thermocouple touching the sample. For in situ WAXS measurements, the test specimens were fixed in the custom build tensile device. The sample was deformed to $200 \%$ strain at $T_{\text {deform }}$ after annealing at $75^{\circ} \mathrm{C}$ for $10 \mathrm{~min}$, and then cooled down to $0^{\circ} \mathrm{C}$ and kept for $10 \mathrm{~min}$, which was the same procedure as in SMCP. WAXS patterns were collected at each programming stage.

\subsubsection{Small-angle $X$-ray scattering (SAXS)}

SAXS was performed on a Bruker Nanostar diffractometer (Bruker AXS, Karlsruhe, Germany), operating $40 \mathrm{kV}$ and $35 \mathrm{~mA}$ on a copper anode. Point focussed X-rays were monochromated and parallelized by Montel-optics and collimated by a 750/ $400 / 1000 \mu \mathrm{m}$ 3-pinhole combination, thus a $400 \mu \mathrm{m}$ beam having a wavelength of $0.15418 \mathrm{~nm}(\mathrm{CuK} \alpha)$ was obtained. The distance sample to the detector was $1070 \mathrm{~mm}$ calibrated with Silver behenate standard. A Vantec-2000 detector $(2048 \times 2048$ pixel, $68 \mu \mathrm{m}$ pixel size) was employed to record scattered intensities, the primary beam was stopped $(6 \mathrm{~mm}$ lead beamstop) close before the detector. The primary and secondary beam paths as well as the sample chamber were operated under vacuum $\left(\sim 10^{-3} \mathrm{mbar}\right)$. Samples were placed into a small powder-sample holder ( $0.2 \mathrm{~mm}$ thickness) and exposed $1 \mathrm{~h}$ to obtain a two dimensional scattering pattern which was corrected for spatial distortion and background subtracted (weighted with sample transmission). Isotropic scattering patterns were integrated (azimuthal average over $360^{\circ}$ ) by 5 -point binning with a $0.001^{\circ}(2 \theta)$ step size from $2 \theta=0.1$ to $3.2^{\circ}$ leading into one-dimensional scattering curves of scattered intensity $v s$. scattering angle $(I$ vs. $2 \theta)$. Anisotropic scattering patterns were integrated over a $10^{\circ}$ wide azimuthal range along the axis of symmetry (fiber axis, $s_{3}$ ) Furthermore scattering angle was converted into scattering vector s, being $|s|=s=(2 / \lambda) \sin \theta$ and a Kratky-plot (Lorenz correction $I s^{2} v s . s$ ) was utilized to extract the long period $L$ from the position of the peak maxima as $L=s^{-1}[16]$.

\subsubsection{Toluene vapor treatment}

The deformed specimens were treated in a vacuum desiccator which was first evacuated and then filled with saturated toluene vapor for $45 \mathrm{~min}$. The lengths of deformed specimens after treatment, $l_{\text {rtoluene, were }}$ recorded to calculate the partial recovery ratio in

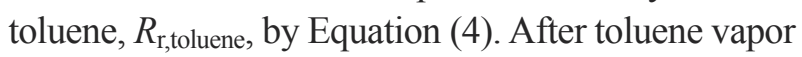
treatment, the sample was heated to $75^{\circ} \mathrm{C}$ to allow for complete recovery. The final recovery ratio after

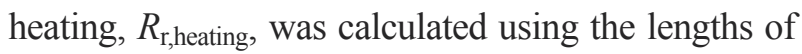
the sample after heating, $l_{\mathrm{r} \text {,heating }}$ according to Equation (5). The content of toluene which was absorbed in the specimens was $8.0 \%$, which was detected by GPC.

$$
\begin{aligned}
& R_{\mathrm{r}, \text { touluene }}=\frac{l_{\varepsilon}-l_{\mathrm{r}, \text { touluene }}}{l_{\varepsilon}-l_{0}} \\
& R_{\mathrm{r}, \text { heating }}=\frac{l_{\varepsilon}-l_{\mathrm{r}, \text { heating }}}{l_{\varepsilon}-l_{0}}
\end{aligned}
$$

where $l_{0}$ is the original length of sample and $l_{\varepsilon}$ is the deformed length of sample.

The content of toluene, which was absorbed in the vapor treated PCL-PIBMD test specimens, was quantified by chromatography experiments using the GPC equipment described in 2.3.1. A series of DMF/ toluene mixtures with varying toluene concentration ranging from 0.02 to $10 \mathrm{wt} \%$ were analyzed with the GPC system for creation of a calibration curve. $0.1 \mathrm{~g}$ pieces were cut from the middle of the deformed specimens after toluene vapor treatment and then 
dissolved in DMF resulting in a $0.2 \mathrm{wt} \%$ concentration and then investigated with the GPC system. The obtained toluene signal was evaluated by using the standard calibration curve.

\section{Results and discussion}

\subsection{Thermal properties}

The thermal properties of deformed PCL-PIBMD films were examined using DSC and compared to that obtained for a preconditioned non-deformed sample (see paragraph 2.3.3). As shown in Figure 1, only a PIBMD melting peak at $168^{\circ} \mathrm{C}$ can be observed in the non-deformed PIBMD sample. The reason might be that the existing PIBMD crystalline domains highly restricted the crystallization of PCL domains during the preconditioning procedure when cooled from 75 to $0^{\circ} \mathrm{C}$ with a cooling rate of $5^{\circ} \mathrm{C} \cdot \mathrm{min}^{-1}$. Therefore, before deformation at 20 or $50^{\circ} \mathrm{C}$, only PIBMD crystals existed in PCL-PIBMD, while all PCL domains were in the amorphous state. The PIBMD amorphous phase with a $T_{\mathrm{g}, \mathrm{PIBMD}} \approx 42^{\circ} \mathrm{C}$ is in the glassy state at $20^{\circ} \mathrm{C}$ or in the rubbery state at $50^{\circ} \mathrm{C}$. After deformation at 20 or $50^{\circ} \mathrm{C}$, both PCL and PIBMD melting peaks were observed in the heating scan, demonstrating that the generation of oriented PCL chains during deformation facilitated the crystallization of PCL domains. A magnified view of the PCL melting peaks is shown in Figure 1b. A pronounced PCL melting peak in the range from 26 to $45^{\circ} \mathrm{C}$ with $\Delta H_{\mathrm{m}, \mathrm{PCL}}=27 \mathrm{~J} \cdot \mathrm{g}^{-1}$ was obtained for the sample deformed at $20^{\circ} \mathrm{C}$, while deformation at $50^{\circ} \mathrm{C}$ resulted in a broad endothermic peak ranging from 27 to $54^{\circ} \mathrm{C}$, having a slightly higher $\Delta H_{\mathrm{m}, \mathrm{PCL}}$ of $29 \mathrm{~J} \cdot \mathrm{g}^{-1}$. The difference in the melting temperature interval indicates that PCL crystals with a higher crystal thickness exist only in samples deformed at $50^{\circ} \mathrm{C}$. As shown in Table 1, the melting enthalpies of PCL domains in the sample deformed at $50^{\circ} \mathrm{C}$ were higher than the sample deformed at $20^{\circ} \mathrm{C}$, suggesting a higher degree of crystallinity of PCL domains after deformation at a higher $T_{\text {deform }}$. The variation of $T_{\text {deform }}$ did not significantly influence the melting enthalpy of the PIBMD crystals $\left(27 \sim 29 \mathrm{~J} \cdot \mathrm{g}^{-1}\right)$. Compared to the non-deformed samples with a PIBMD melting enthalpy of $22 \mathrm{~J} \cdot \mathrm{g}^{-1}$, it can be anticipated that strain-induced crystallization was responsible for the observed increase in crystallinity when the samples were deformed to $200 \%$.

\subsection{Surface morphologies}

AFM experiments were performed to visualize the surface morphologies of PCL-PIBMD samples after deformation at various temperatures, as presented in Figure 2. Polymer crystals as typical spherulites,

Table 1. Thermal properties of deformed and non-deformed PCL-PIBMD solution cast films calculated from DSC measurements

\begin{tabular}{|c|c|c|c|c|}
\hline $\begin{array}{c}T_{\text {deform }} \\
{\left[{ }^{\circ} \mathrm{C}\right]}\end{array}$ & $\begin{array}{c}T_{\mathrm{m}, \mathrm{PCL}} \\
{\left[{ }^{\circ} \mathrm{C}\right]}\end{array}$ & $\begin{array}{c}\Delta \boldsymbol{H}_{\mathrm{m}, \mathrm{PCL}} \\
{\left[\mathbf{J} \cdot \mathrm{g}^{-1}\right]}\end{array}$ & $\begin{array}{c}T_{\mathrm{m}, \mathrm{PIBMD}} \\
{\left[{ }^{\circ} \mathrm{C}\right]}\end{array}$ & $\begin{array}{c}\Delta H_{\mathrm{m}, \mathrm{PIBMD}} \\
{\left[\mathrm{J} \cdot \mathrm{g}^{-1}\right]}\end{array}$ \\
\hline Non-programmed & - & - & 168 & 22 \\
\hline 20 & 40 & 21 & 168 & 27 \\
\hline 50 & 41 & 29 & 170 & 29 \\
\hline
\end{tabular}

Note: the estimated error for $T$ is $\pm 1^{\circ} \mathrm{C}$, for $\Delta H$ is $\pm 2 \mathrm{~J} \cdot \mathrm{g}^{-1}$.
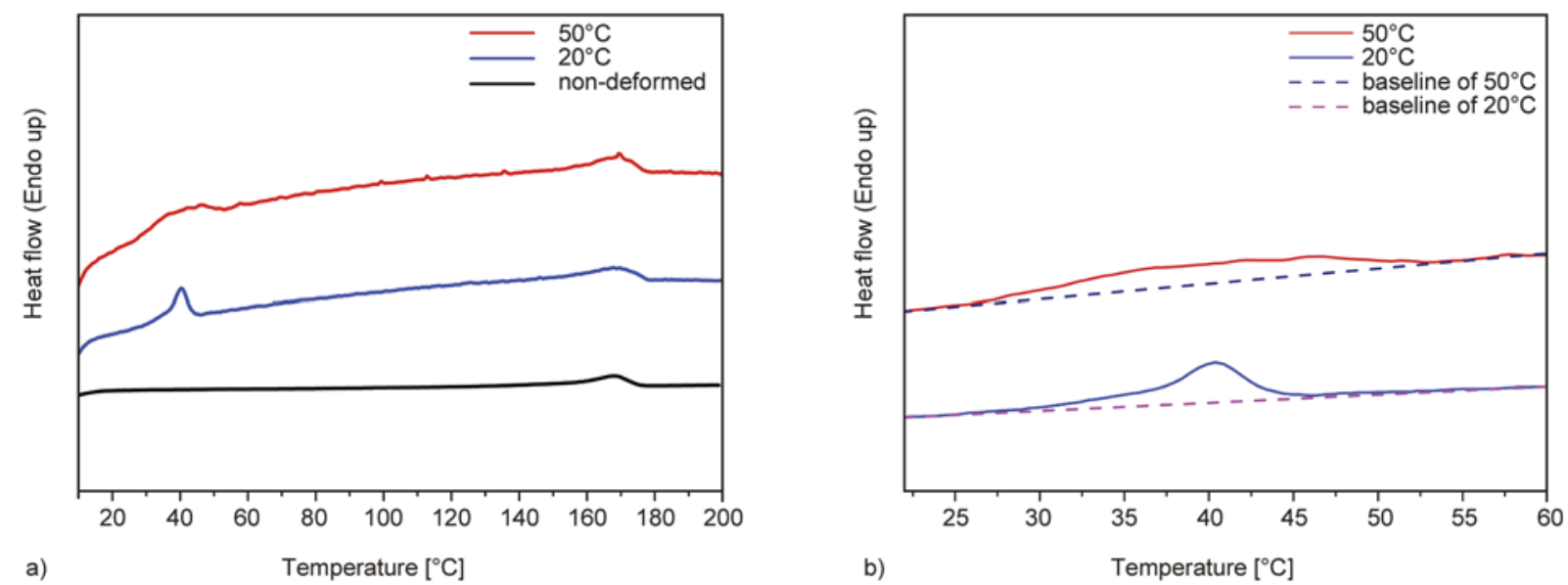

Figure 1. DSC heating curves of (a) deformed and non-deformed PCL-PIBMD solution cast films and (b) maginified view of PCL crystals melting peaks 


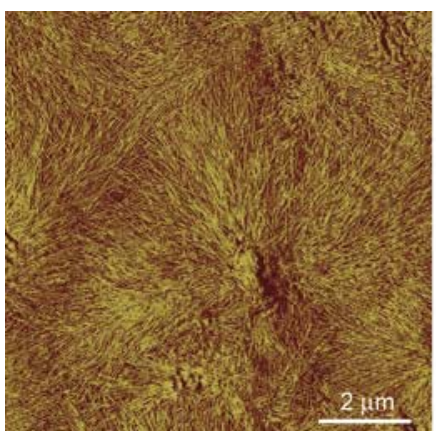

a)

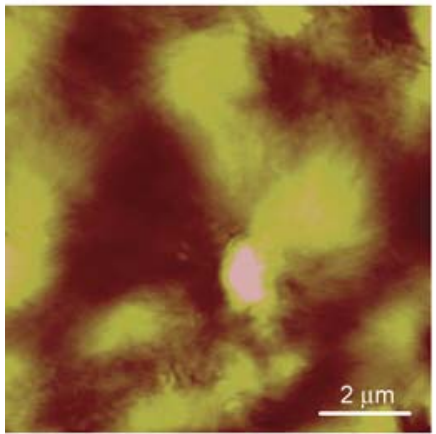

d)

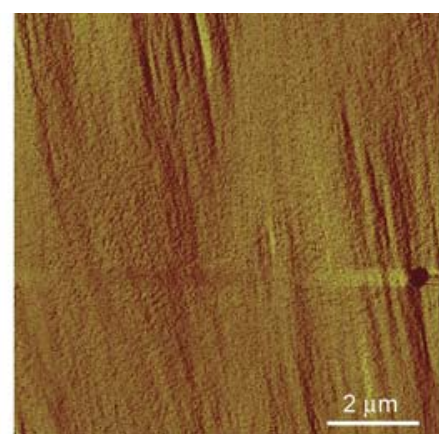

b)

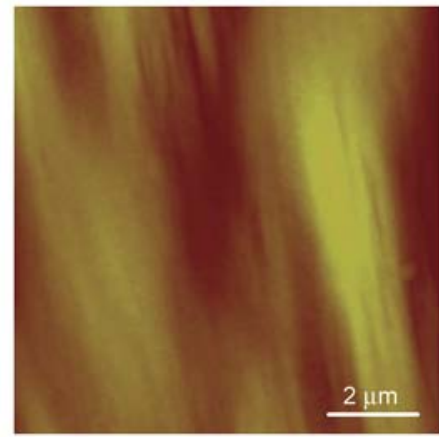

e)

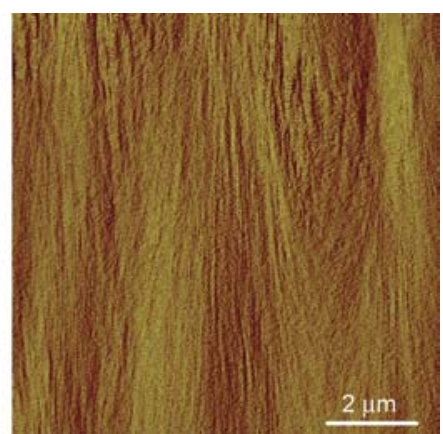

c)

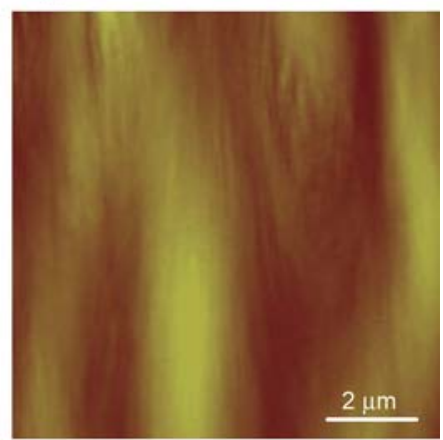

f)

Figure 2. AFM phase images (a, b, c) and height images (d, e, f) of PCL-PIBMD films before (a, d) and after deformation to $200 \%$ strain at $50^{\circ} \mathrm{C}(\mathrm{b}, \mathrm{e})$ and $20^{\circ} \mathrm{C}(\mathrm{c}, \mathrm{f})$. The deformation direction was vertical

which are composed of highly ordered edge-on lamellae, were observed in the non-deformed sample as shown in Figures $2 \mathrm{a}$ and $2 \mathrm{~d}$. The large spherulites did not change evidently when increasing the temperature from 20 to $60^{\circ} \mathrm{C}$ (not presented here), indicating that those crystals originated from PIBMD domains. These results matched with the DSC data. It can also be observed that PIBMD crystals are enriched on the top surface of solution cast film. Further investigations with the spin coated PCL-PIBMD films (data not shown here) demonstrated that that PCL segments were preferentially enriched on the top layer in the molten state, indicating a smaller surface energy of PCL compared to PIBMD. The newly formed PIBMD crystals broke out the ordered phase separated morphology and fully wetted the free surface, while the crystallization of PCL domains was confined in the PIBMD lamellae, forming fractionated crystals. Thus, only large PIBMD spherulites can be observed on the topography of PCL-PIBMD films. More importantly, compared to the initial morphology without deformation, it can be illustrated from AFM phase images that the PIBMD spherulites were deformed along the deformation direction, as shown in Figures $2 b-2 c$ and $2 e-2 f$. In addition, higher levels of structural orientations of PIBMD crystals can be observed if PCL-PIBMD film was deformed at $50^{\circ} \mathrm{C}$.

\subsection{Crystalline structures}

For exploring the nanostructural changes during the deformation of PCL-PIBMD samples in-situ 2D WAXS patterns were recorded at different temperatures, which are displayed in Figure $3 \mathrm{a}$. At $50^{\circ} \mathrm{C}$, a strong reflection as an inner bright ring $\left(2 \theta=8.8^{\circ}\right)$ was identified with several other weak reflections as shown in Figures 3a (I and IV), all of which belong to the PIBMD crystals. Isotropic scattering indicated that randomly distributed PIBMD lamellae did not present evident orientation before deformation. With stretching to $200 \%$ at $50^{\circ} \mathrm{C}$ (Figure 3a II), an equatorial scattering maximum appeared at the inner ring $\left(2 \theta=8.8^{\circ}\right)$ of PIBMD crystal reflections as indicated by the arrow, illustrating the orientation of PIBMD crystals perpendicular to the deformation direction. The deformed sample was then cooled to $0^{\circ} \mathrm{C}$ (Figure $3 \mathrm{a}$ III) while the deformation was fixed. The ring of (110) reflection $\left(2 \theta=21.3^{\circ}\right)$ showed a strong equatorial scattering maximum, which suggested the generation of PCL crystals perpendicular to the deforming direction. For the sample deformed at $20^{\circ} \mathrm{C}$ (Figure $3 \mathrm{a} \mathrm{V}$ ), the equatorial (110) scattering maximum confirmed that the PCL crystals appeared only after stretching at $20^{\circ} \mathrm{C}$ (highlighted by an arrow). This indicates that the strain-induced crystallization of PCL domains 
occurred during the stretching and the newly generated PCL crystals aligned perpendicular to the deformation direction. Usually, crystals generated by strain-induced crystallization exhibit highly ordered structures compared to that formed by thermalinduced crystallization during cooling. This conclusion could be confirmed by the DSC results, where a broad PCL melting peak was obtained for the sample deformed at $50^{\circ} \mathrm{C}$ and a smaller pronounced melting peak when programmed at $20^{\circ} \mathrm{C}$.

No difference in the nanostructure was observed when the samples were further cooled to $0^{\circ} \mathrm{C}$ (Figure $3 \mathrm{a}$ VI). The size of PIBMD crystals $\left(l_{\mathrm{c}, \text { PIBMD }}\right)$ after deformation was calculated and shown in Table 2. Compared to the non-deformed sample, the size of PIBMD crystals decreased from 16.4 to $15.8 \sim 15.9 \mathrm{~nm}$ after deformation at 50 or $20^{\circ} \mathrm{C}$. These results suggested that the fragmentation of PIBMD crystals occurred during deformation and its level
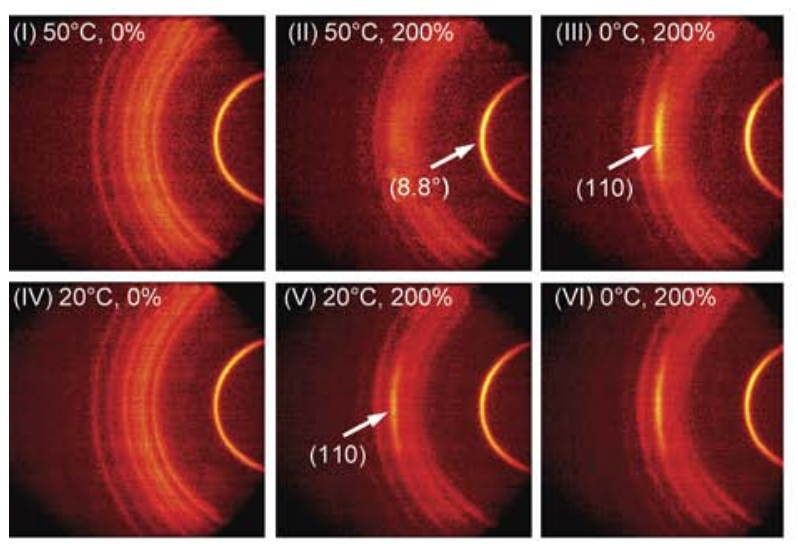

a)
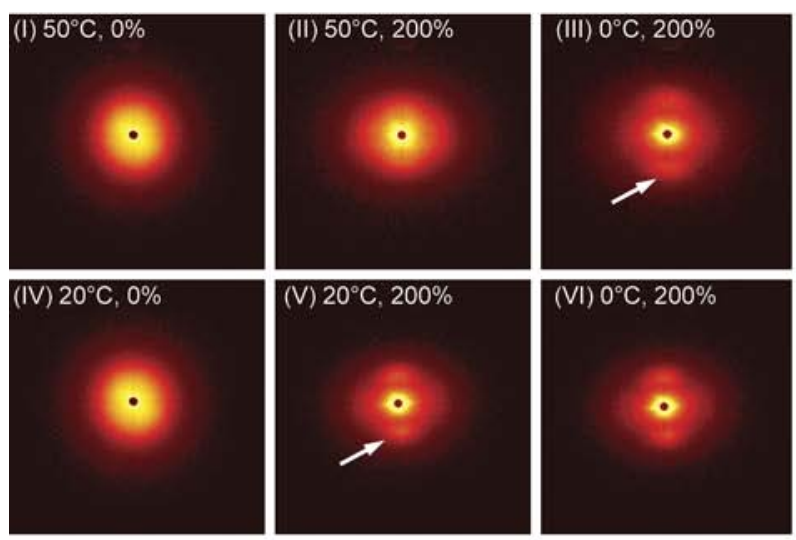

b) was similar when PCL-PIBMD was deformed to $200 \%$ at 50 or $20^{\circ} \mathrm{C}$.

For quantification of the resulting degree of orientation of the crystalline structures, the corresponding azimuthal scans of the WAXS patterns were analyzed. Here, the intensity distribution of the ring (110) $\left(2 \theta=21.3^{\circ}\right)$ from the PCL crystal reflections were explored at each deformation stage as shown in Figure $3 \mathrm{c}$ and $3 \mathrm{~d}$, which was corresponding to the SMCP. The full width at half maximum (FWHM) of crystal structures were listed in Table 2. Before deformation, no peaks can be found in the profiles, indicating that no PCL crystals existed in the nondeformed samples. In the azimuthal profiles obtained after deformation at $50^{\circ} \mathrm{C}$ also no PCL crystals are present, while after cooling to $0^{\circ} \mathrm{C}$ a pronounced increase in orientation was obtained $\left(\mathrm{FWHM}_{\mathrm{PCL}}=\right.$ $25.7^{\circ}$ ) caused by newly generated PCL crystals. In contrast, the azimuthal profiles of the sample

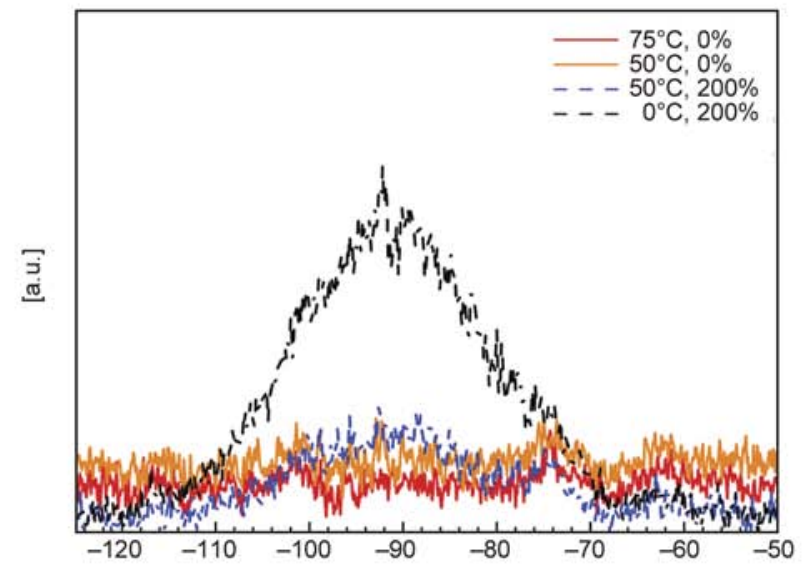

c)

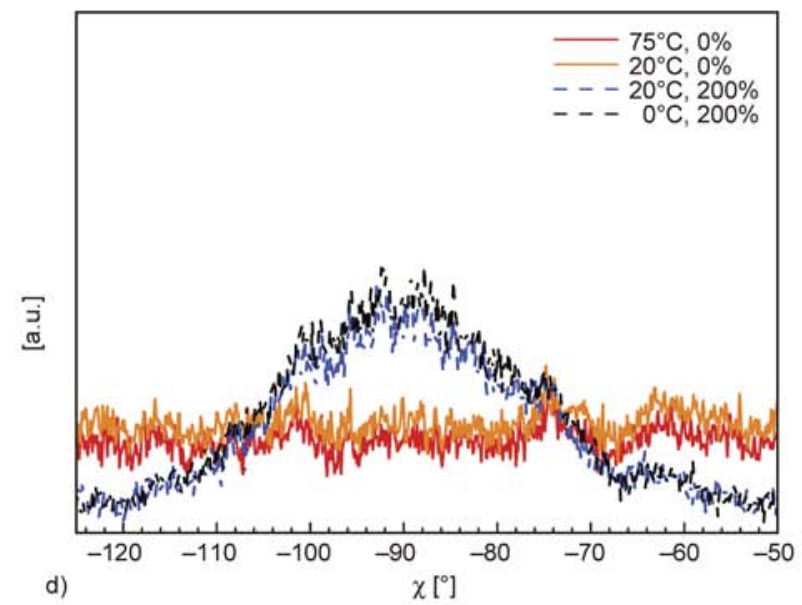

Figure 3. WAXS (a) and SAXS (b) patterns of PCL-PIBMD films (I, IV) before and (II, V) after deformation to $200 \%$ strain at (I, II) $50^{\circ} \mathrm{C}$ and (IV, V) $20^{\circ} \mathrm{C}$ and cooled to (III, VI) $0^{\circ} \mathrm{C}$, respectively. Intensity distribution of (a) the ring (110) $\left(2 \theta=21.3^{\circ}\right)$ from PCL crystal reflections from WAXS patterns when samples were deformed at (c) $20^{\circ} \mathrm{C}$ and (d) $50^{\circ} \mathrm{C}$. The deformation direction was vertical 
deformed at $20^{\circ} \mathrm{C}\left(\mathrm{FWHM}_{\mathrm{PCL}}=33.3^{\circ}\right)$ and fixed at $0^{\circ} \mathrm{C}\left(\mathrm{FWHM}_{\mathrm{PCL}}=32.3^{\circ}\right)$, were found to be almost identical (see Figure 3c), indicating that a lower degree of orientation of PCL crystals is achieved by deformation at $20^{\circ} \mathrm{C}$. In addition, the azimuthal analysis of the PIBMD crystal structure was performed (Figure 3d). Here a higher degree of orientation could be obtained when the samples were deformed at $50^{\circ} \mathrm{C}$ compared to the deformation at $20^{\circ} \mathrm{C}$. This result is in good agreement with the interpretation of the AFM analysis.

During programming at $50^{\circ} \mathrm{C}$ the overall applied deformation can be solely fixed by the PIBMD crystals existing at $50^{\circ} \mathrm{C}$, whereby the oriented amorphous PCL domains can crystallize in the subsequent cooling to $0^{\circ} \mathrm{C}$. On the contrary, a difference is given when deforming the multiblock copolymer at $20^{\circ} \mathrm{C}$. Here the PCL domains form strain-induced crystals during the deformation process. Thus, the deformability of the amorphous PCL domains would be additionally restricted by newly formed PCL crystals and glassy PIBMD domains. Therefore, a decrease in degree of orientation of PCL and PIBMD chains represented by lower FWHM values is caused. As the PCL domains exhibit a low glass transition temperature around $-60^{\circ} \mathrm{C}$, it can be assumed that the relaxation of the rubbery PCL chains at 20 or $50^{\circ} \mathrm{C}$ is almost similar, but that the chain deformability (which is higher at $50^{\circ} \mathrm{C}$ ) is predominantly controlling the achievable degree of orientation after programming.

The changes in the lamellar structure during deformation can be extracted directly from the in-situ 2D SAXS patterns. As shown in Figures $3 \mathrm{~b}$ (I and IV), before deformation, the SAXS patterns exhibited single isotropic scattering related to the stacks of randomly oriented chain-folded PIBMD lamellae at $50^{\circ} \mathrm{C}$, suggesting that no preferred orientation existed in non-deformed samples. After deformation up to a strain of $200 \%$ at $50^{\circ} \mathrm{C}$ (Figure $3 \mathrm{~b} \mathrm{II}$ ), the pattern became oblate, indicating the scattering maximum along the meridional direction (parallel to deformation direction) shifted to a lower angle, whereas the scattering maximum in equatorial direction (vertical to deformation direction) moved to a higher value. Followed by deforming at $50^{\circ} \mathrm{C}$, samples were cooled to $0^{\circ} \mathrm{C}$ to fix the temporary shape (Figure $3 \mathrm{~b}$ III). Two scattering maxima appeared in meridian, suggesting the generation of PCL crystalline lamellae during cooling, which were oriented perpendicular to the deformation direction. For the PCL-PIBMD sample stretched at $20^{\circ} \mathrm{C}$ to $200 \%$ (Figure $3 \mathrm{~b} \mathrm{~V}$ ), two strong scattering maxima were clearly visible along the meridional direction, which further prove that the strain-induced PCL crystals were vertical to the deformation direction during stretching. After fixing the temporary shape at $0^{\circ} \mathrm{C}$ (Figure $3 \mathrm{~b} \mathrm{VI}$ ), no evident changes can be observed compared to the deformed sample at $20^{\circ} \mathrm{C}$. The shift of the scattering maximum in SAXS patterns was related to the changes in the long period $(L)$, which are summarized in Table 2. The long period in meridional direction $\left(L_{\mathrm{mer}}\right)$ increased from 13.3 to $13.5 \mathrm{~nm}$ while the long period in equator $\left(L_{\text {equ }}\right)$ was reduced from 13.3 to $10.5 \mathrm{~nm}$ after deformation to $200 \%$ at $50^{\circ} \mathrm{C}$. It can be considered that the deformation enlarged the average spacing between the lamellae aligned perpendicularly to the deformation direction leading to the increase in $L_{\text {mer, }}$, while the space between the lamellae which are parallel to the deformation direction decreased. After cooling to $0^{\circ} \mathrm{C}$, the reductions in both $L_{\text {mer }}$ and $L_{\text {equ }}$ were observed. The reason could be the generation of small PCL crystals among the PIBMD lamellae. When the sample was deformed at $20^{\circ} \mathrm{C}$, the $L_{\text {equ }}$ decreased to $9.9 \mathrm{~nm}$, while $L_{\text {mer }}$ turned to $11.1 \mathrm{~nm}$. The reduction in both $L_{\mathrm{mer}}$ and $L_{\text {equ }}$ at $20^{\circ} \mathrm{C}$ suggested that the crystal structures generated during stretching resulted from strain-induced crystallization of PCL domains. Only a slight difference can be observed when the sample was cooled

Table 2. Thermal properties and crystal structures obtained or calculated from DSC, WAXS and SAXS measurements

\begin{tabular}{|l|c|c|c|c|c|c|}
\hline $\begin{array}{c}\boldsymbol{T}_{\text {deform }} \\
{\left[{ }^{\circ} \mathbf{C}\right]}\end{array}$ & $\begin{array}{c}\boldsymbol{T} \\
{\left[{ }^{\circ} \mathbf{C}\right]}\end{array}$ & $\begin{array}{c}\boldsymbol{L}_{\text {equ }} \\
{[\mathbf{n m}]}\end{array}$ & $\begin{array}{c}\boldsymbol{L}_{\text {mer }} \\
{[\mathbf{n m}]}\end{array}$ & $\begin{array}{c}\boldsymbol{l}_{\mathbf{c}, \text { PIBMD }} \\
{[\mathbf{n m}]}\end{array}$ & $\begin{array}{c}\text { FWHM } \\
{\left[{ }^{\circ}\right]}\end{array}$ & $\begin{array}{c}\text { FWMHD } \\
{\left[{ }^{\circ}\right]}\end{array}$ \\
\hline Non-programmed & 20 & 13.0 & 13.0 & 16.4 & - & - \\
\hline Non-programmed & 50 & 13.3 & 13.3 & 16.4 & - & - \\
\hline 50 & 50 & 10.5 & 13.5 & 15.8 & 64.3 & - \\
\hline 50 & 0 & 9.0 & 12.8 & 15.9 & 62.9 & 25.7 \\
\hline 20 & 20 & 9.9 & 11.1 & 15.9 & 85.8 & 33.3 \\
\hline 20 & 0 & 8.9 & 10.9 & 15.8 & 84.3 & 32.3 \\
\hline
\end{tabular}

Note: $L_{\text {equ }}$ and $L_{\text {mer }}$ were calculated from SAXS results and $l_{\mathrm{c} \text {,PIBMD }}$ was calculated from WAXS data. The estimated error for $L$ and $l_{\mathrm{c}}$ are $\pm 0.2 \mathrm{~nm}$ and for FWHM is $0.7^{\circ}$. 
down to $0^{\circ} \mathrm{C}$ after deformation since $T_{\text {deform }}$ was already lower than $T_{\mathrm{g}, \mathrm{PIBMD}}$ and $T_{\mathrm{m}, \mathrm{PCL}}$. The SAXS results fully agreed with the WAXS results.

\subsection{Shape-memory properties}

The shape-memory properties of solution cast PCLPIBMD films performed at two $T_{\text {deform }} \mathrm{s}$ were measured by cyclic, thermomechnical tensile tests. The stress-temperature-strain curves of the first cycle are shown in Figure 4. In SMCP, the PCL-PIBMD specimens were stretched to a strain of $\varepsilon_{\mathrm{m}}$ of $200 \%$ at a deformation rate of $1 \mathrm{~mm} \cdot \mathrm{min}^{-1}$. The $T_{\text {deforms }}$ were chosen as 50 and $20^{\circ} \mathrm{C}$, respectively, which was above or below both $T_{\mathrm{m}, \mathrm{PCL}}$ and $T_{\mathrm{g} \text {,PIBMD. The }}$ deformed shapes were fixed when the temperature was decreased to $T_{\text {low }}$ of $0^{\circ} \mathrm{C}$. Finally, by heating the samples to $75^{\circ} \mathrm{C}$ under stress-free or constant-strain conditions the recovery was initiated.

Table 3 lists the shape-memory properties determined for the PCL-PIBMD samples programmed at different $T_{\text {deform }}$. Excellent values for $R_{\mathrm{f}}$ above $92 \%$ as well as $R_{\mathrm{r}}$ around $90 \%$ in the first cycle and $R_{\mathrm{r}} \approx 99 \%$ in the $2^{\text {nd }}$ and $3^{\text {rd }}$ cycle were reached for both samples. The $T_{\mathrm{sw}}$ decreased from 44 to around $39^{\circ} \mathrm{C}$ as well as the temperature where the maximum recovery force occurred $\left(T_{\sigma, \max }\right)$ was reduced from 56 to $30^{\circ} \mathrm{C}$ when $T_{\text {deform }}$ was reduced from 50 to $20^{\circ} \mathrm{C}$. This effect could be caused by the different structures of PCL crystals, as demonstrated by DSC curves, and different degree of orientation of PIBMD domains, as shown in AFM images. In addition, a higher stress $\sigma\left(\varepsilon_{\mathrm{m}}\right)$ was required to achieve the same strain at $20^{\circ} \mathrm{C}$ since the PIBMD amorphous phase was in glassy state. In addition, the ratio of $\sigma_{\max } / \sigma\left(\varepsilon_{\mathrm{m}}\right)$ decreased largely from 60.0 to $38.2 \%$ when decreasing the $T_{\text {deform }}$ from 50 to $20^{\circ} \mathrm{C}$, suggesting that more energy was dissipated during stretching for the slippage and the fragmentation of PIBMD lamellae.

\subsection{Toluene vapor treatment}

As demonstrated before [7], in case of PCL-PIBMD, both PIBMD amorphous phase and PCL crystalline phase can act as switching domains since they present a similar $T_{\text {trans }}$. Therefore, the temporary shape of deformed samples can be fixed by the crystallization of PCL domains and the vitrification of amorphous PIBMD phase. Since toluene is a good solvent for PCL but a poor solvent for PIBMD, it can be used to trigger the partial recovery of deformed specimens by selectively eliminating PCL crystals by the solvatisation of PCL segments. In addition, since PIBMD amorphous phases still stayed in the glassy state at room temperature after the treatment with toluene vapor (determined by DMTA, not shown here), the temporary shape which is fixed by vitrification of PIBMD amorphous phase cannot recover

Table 3. Shape-memory properties for PCL-PIBMD films programmed to $200 \%$ at 50 and $20^{\circ} \mathrm{C}$, respectively, with the strain rate of $1 \mathrm{~mm} \cdot \mathrm{min}^{-1}$

\begin{tabular}{|c|c|c|c|c|c|c|c|c|c|}
\hline $\begin{array}{c}\boldsymbol{T}_{\text {deform }} \\
{\left[{ }^{\circ} \mathbf{C}\right]}\end{array}$ & $\begin{array}{c}\boldsymbol{R}_{\mathbf{f}(\mathbf{1})} \\
{[\% \mathbf{\%}]}\end{array}$ & \begin{tabular}{c}
$\boldsymbol{R}_{\mathbf{r}(\mathbf{1})}[\mathbf{\%}]$ \\
\hline 50
\end{tabular} & $\begin{array}{c}\boldsymbol{R}_{\mathbf{f}(\mathbf{2}, \mathbf{3})} \\
{[\mathbf{\%}]}\end{array}$ & $\begin{array}{c}\boldsymbol{R}_{\mathbf{r}(\mathbf{2}, \mathbf{3})} \\
{[\mathbf{\%}]}\end{array}$ & $\begin{array}{c}\boldsymbol{T}_{\mathbf{s w}} \\
{\left[{ }^{\circ} \mathbf{C}\right]}\end{array}$ & $\begin{array}{c}\boldsymbol{\sigma}\left(\varepsilon_{\mathbf{m}}\right) \\
{[\mathbf{M P a}]}\end{array}$ & $\begin{array}{c}\boldsymbol{\sigma}_{\max } \\
{[\mathbf{M P a}]}\end{array}$ & $\begin{array}{c}\boldsymbol{\sigma}_{\max } / \boldsymbol{\sigma}\left(\varepsilon_{\mathbf{m}}\right) \\
{[\mathbf{\%}]}\end{array}$ & $\begin{array}{c}\boldsymbol{T}_{\boldsymbol{\sigma}, \max } \\
{\left[{ }^{\circ} \mathbf{C}\right]}\end{array}$ \\
\hline 20 & 96 & 90 & 96 & 99 & 44 & 12.4 & 7.4 & 60.0 & 56 \\
\hline
\end{tabular}

Note: The $R_{\mathrm{f}(1)}, R_{\mathrm{r}(1)}, T_{\mathrm{sw}}$, were determined from the $1^{\text {st }}$ cycle measurement under stress-free recovery; $R_{\mathrm{f}(2,3)}$ and $R_{\mathrm{r}(2,3)}$ were the average values of the $2^{\text {nd }}$ and $3^{\text {rd }}$ cycle measurement under stress-free recovery; $\sigma\left(\varepsilon_{\mathrm{m}}\right), \sigma_{\max }, \sigma_{\max } / \sigma\left(\varepsilon_{\mathrm{m}}\right)$ and $T_{\sigma, \max }$ were determined from the $1^{\text {st }}$ cycle measurement under constant-strain recovery. $R_{\mathrm{r}, \text { toluene }}$ was measured using a centimeter ruler. The estimated errors for $R_{\mathrm{f}}$ and $R_{\mathrm{r}}$ is $\pm 2 \%$, for $T$ is $\pm 2^{\circ} \mathrm{C}$, for $\sigma$ is $\pm 0.5 \mathrm{MPa}$ and for $R_{\mathrm{r}, \text { toluene }}$ is $\pm 4 \%$.
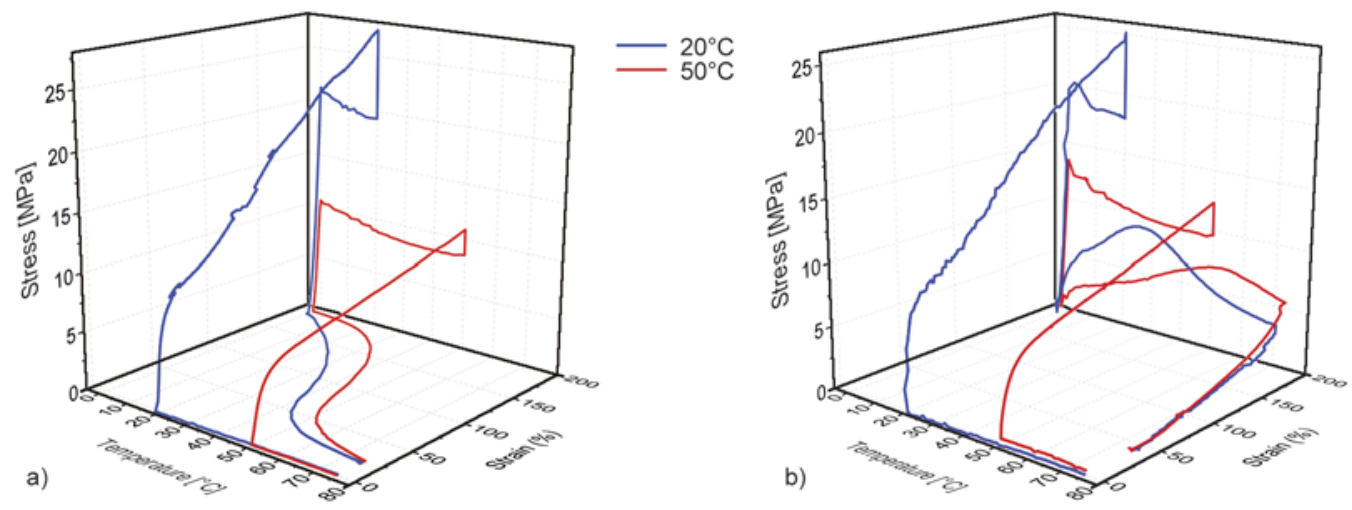

Figure 4. The first cycle curves of cyclic tests of PCL-PIBMD films programmed to $200 \%$ at 50 and $20^{\circ} \mathrm{C}$, respectively, with the strain rate of $1 \mathrm{~mm} \cdot \mathrm{min}^{-1}$ and recovered under (a) stress-free and (b) constant-strain conditions 
considerably. Thus, after placing the deformed specimens in toluene vapor for $45 \mathrm{~min}$ at room temperature, the contributions of $T_{\mathrm{g}, \mathrm{PIBMD}}$ and $T_{\mathrm{m}, \mathrm{PCL}}$ to the SME switching domains can be distinguished. Figure 5 presents the photographic pictures of deformed samples before and after toluene vapor treatment and after reheating to $75^{\circ} \mathrm{C}$ in comparison to a non-deformed sample. It can be observed that the lengths of deformed specimens decreased after $45 \mathrm{~min}$, indicating a partial recovery. DSC measurements were performed to examine the thermal properties of treated samples (not shown here). After toluene vapor treatment, the melting peaks of PCL domains disappeared, suggesting that the PCL crystals were dissolved by vapor toluene. The orientated PCL chains which were fixed by PCL crystals, thus fully recovered driven by increasing the entropy. The PIBMD crystals, however, did not vary considerably during the treatment, demonstrating that (1) the netpoints, or the ability to keep the permanent shape of PCL-PIBMD samples, were not influenced by toluene, and more importantly, (2) the variation in PIBMD amorphous phase could be neglected. Then these samples after the treatment in toluene vapor were reheated to $75^{\circ} \mathrm{C}$, where the orientated chains fixed by vitrification of PIBMD domains were allowed to recover. A second recovery process can be observed and the lengths of deformed samples further reduced. As declared in Table 4, the total recovery ratios after heating, $R_{\mathrm{r} \text {,heating, for samples }}$ deformed at 50 and $20^{\circ} \mathrm{C}$ were comparable with the recovery ratios measured from cyclic, thermomechanical tensile tests. Therefore, the recovery ratio after toluene vapor treatment $\left(R_{\mathrm{r}, \text { toluene }}\right)$ can be con-
Table 4. The recovery ratio after toluene vapor treatment and heating procedure for PCL-PIBMD films programmed to $200 \%$ at 50 and $20^{\circ} \mathrm{C}$, respectively, with the strain rate of $1 \mathrm{~mm} \cdot \mathrm{min}^{-1}$

\begin{tabular}{|c|c|c|c|}
\hline $\begin{array}{c}\boldsymbol{T}_{\text {deform }} \\
{\left[{ }^{\circ} \mathbf{C}\right]}\end{array}$ & $\begin{array}{c}\boldsymbol{R}_{\mathbf{r} \text {,toluene }} \\
{[\mathbf{\%}]}\end{array}$ & $\begin{array}{c}\boldsymbol{R}_{\mathbf{r} \text {,heating }} \\
{[\mathbf{\%}]}\end{array}$ & $\begin{array}{c}\boldsymbol{R}_{\mathbf{r} \text {,toluene }} / \boldsymbol{R}_{\mathbf{r} \text {,heating }} \\
{[\mathbf{\%}]}\end{array}$ \\
\hline 50 & 73 & 88 & 82.9 \\
\hline 20 & 87 & 90 & 96.7 \\
\hline
\end{tabular}

Note: $R_{\mathrm{r}, \text { toluene }}$ and $R_{\mathrm{r}, \text { heating }}$ were measured using a centimeter ruler after toluene vapor treatment and heating to $75^{\circ} \mathrm{C}$, respectively. The estimated errors for $R_{\mathrm{r}, \text { toluene }}$ and $R_{\mathrm{r}, \text { heating }}$ are $\pm 2 \%$.

sidered as the absolute recovery ratio resulting from PCL crystals as the switching domains, while the ratio of $R_{\mathrm{r} \text {,toluene }} / R_{\mathrm{r} \text {,heating }}$ can be defined as the relative contribution of PCL crystals to the total recovery of deformed PCL-PIBMD specimens. Table 4 shows that the $R_{\mathrm{r} \text {,toluene value of samples deformed }}$ at $20^{\circ} \mathrm{C}$ was larger than that deformed at $50^{\circ} \mathrm{C}$,

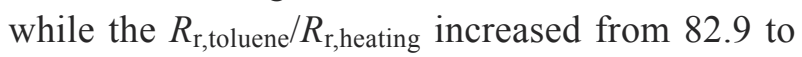
$96.7 \%$ when $T_{\text {deform }}$ changed from 50 to $20^{\circ} \mathrm{C}$. These results indicated that the temporary shape of the samples deformed at $20^{\circ} \mathrm{C}$ was almost totally fixed by the strain-induced crystallization of PCL domains.

Based on all the obtained data and results, the mechanisms of structural variations of PCL-PIBMD specimens programmed to $200 \%$ strain at 50 and $20^{\circ} \mathrm{C}$ are discussed in the following. In the semi-crystalline MBC of PCL-PIBMD, PCL amorphous domains, PIBMD amorphous domains, and PIBMD crystalline domains existed before deformation. The uniaxial deformation at $50^{\circ} \mathrm{C}$ first resulted in the orientation of PIBMD and PCL amorphous phases. With increasing the strain, the stress was transferred from orientated amorphous chains to PIBMD crystals, leading to their fragmentation.

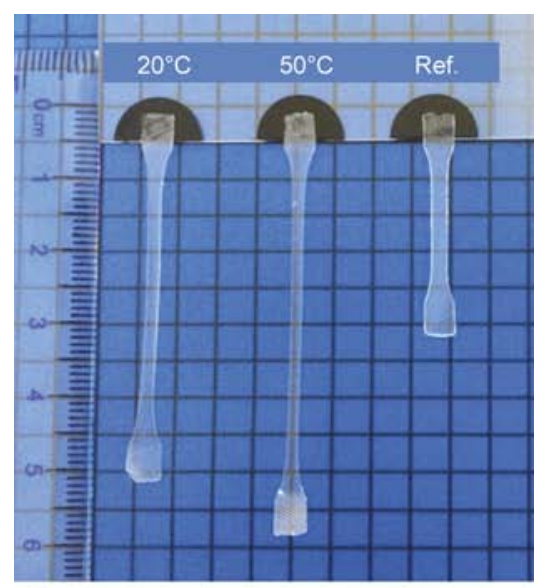

a)

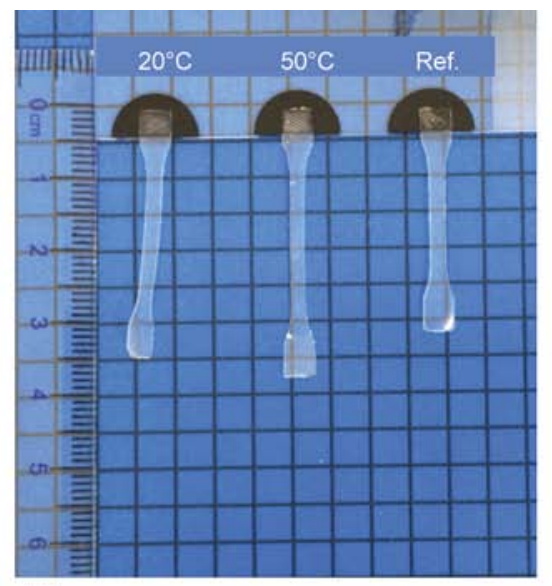

b)

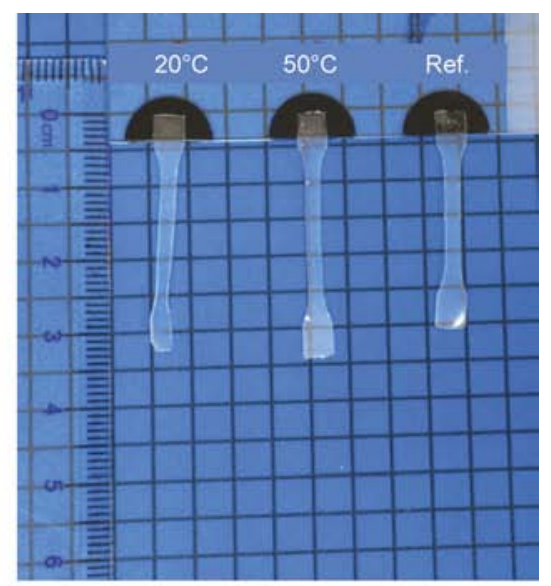

c)

Figure 5. Photos of deformed PCL-PIBMD samples (a) after deformation, (b) after toluene vapor treatment and (c) after heating to $75^{\circ} \mathrm{C}$ in comparison to a non-deformed sample as a reference. For the deformed films, the strain was $200 \%$ with the strain rate of $1 \mathrm{~mm} \cdot \mathrm{min}^{-1}$ and the deformation temperatures were 50 and $20^{\circ} \mathrm{C}$, respectively. 
At $50^{\circ} \mathrm{C}$, strain-induced crystallization of PCL domains was negligible, since the temperature was

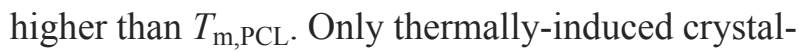
lization of PCL domains occurred during the subsequent cooling process, in which the entangled polymer chains preferred to form crystals with chain-folded conformation. However, at $20^{\circ} \mathrm{C}$ uniform chain-extended crystal structures were generated because of strain-induced crystallization. A lower $T_{\mathrm{m}, \mathrm{PCL}}$ and its narrower range, thus, were achieved, correspondingly decreasing $T_{\mathrm{sw}}$ and $T_{\sigma, \max }$. The amorphous PIBMD phase stayed in rubbery or glassy state at 50 or $20^{\circ} \mathrm{C}$, respectively. When the sample was deformed at $50^{\circ} \mathrm{C}$, both PCL and PIBMD amorphous phases can be oriented. After cooling down the temperature to $0^{\circ} \mathrm{C}$, the oriented PIBMD amorphous phase was fixed by its vitrification. Therefore, both PCL crystals and PIBMD amorphous phase can contribute to the fixation of the temporary shape.

When the PCL-PIBMD samples were programmed at $20^{\circ} \mathrm{C}$, however, the PIBMD amorphous phase was in the glassy state. Therefore, the chain orientation was mainly restricted to PCL amorphous phase and the temporary shape was fixed mainly by the crystallization of PCL domains. For the same reason, a higher stress was required for deforming the sample and more energy dissipation was observed during stretching, generating the larger $\sigma\left(\varepsilon_{\mathrm{m}}\right)$ but smaller $\sigma_{\max } / \sigma\left(\varepsilon_{\mathrm{m}}\right)$ at $20^{\circ} \mathrm{C}$.

\section{Conclusions}

In PCL-PIBMD MBCs, the amorphous PIBMD domains and crystallizable PCL domains can serve as switching domains, while the PIBMD crystals act as physical netpoints determining the permanent shape. The structural evolution of PCL-PIBMD samples during deformation depended on the deformation temperature and resulted in different contributions of PCL crystals and amorphous PIBMD domains to the switching domains. When the samples were deformed at $50^{\circ} \mathrm{C}$, which was above $T_{\mathrm{m}, \text { PCL }}$ and $T_{g, \text { PIBMD }}$, both PCL and PIBMD amorphous domains were oriented. The temporary shape of deformed PCL-PIBMD, thus, was fixed by the thermally-induced chain-folded PCL crystals and vitrification of PIBMD domains, leading to their joint contribution to switching domains. However, when the samples were deformed at $20^{\circ} \mathrm{C}$, which is below $T_{\mathrm{m}, \mathrm{PCL}}$ and $T_{\mathrm{g}, \mathrm{PIBMD}}$, only PCL crystallizable domains acted as switching domains by straininduced crystallization, since PIBMD amorphous phase was in the glassy state. In such a case a higher programming stress is required and more energy dissipation occurred during deformation when compared to $T_{\text {deform }}=50^{\circ} \mathrm{C}$. Here we could demonstrate that the results achieved by a combination of structural and thermo-mechanical investigations are useful for understanding of complicated SME mechanisms in MBCs containing two crystallizable segments. More importantly, this work offers a new method to clarify and adjust the relative contribution of crystalline and amorphous switching domains with overlapping or almost identical transition temperature ranges in such MBC.

\section{References}

[1] Behl M., Razzaq M. Y., Lendlein A.: Multifunctional shape-memory polymers. Advanced Materials, 22, 3388-3410 (2010).

DOI: $10.1002 / \mathrm{adma} .200904447$

[2] Xie T.: Recent advances in polymer shape memory. Polymer, 52, 4985-5000 (2011). DOI: $10.1016 /$ j.polymer.2011.08.003

[3] Karger-Kocsis J., Kéki S.: Biodegradable polyesterbased shape memory polymers: Concepts of (supra) molecular architecturing. Express Polymer Letters, 8, 397-412 (2014).

DOI: $10.3144 /$ expresspolymlett.2014.44

[4] Kolesov I. S., Radusch H-J.: Multiple shape-memory behavior and thermal-mechanical properties of peroxide cross-linked blends of linear and short-chain branched polyethylenes. Express Polymer Letters, 2, 461-473 (2008).

DOI: 10.3144/expresspolymlett.2008.56

[5] Kang S. M., Lee S. J., Kim B. K.: Shape memory polyurethane foams. Express Polymer Letters, 6, 63-69 (2012).

DOI: $10.3144 /$ expresspolymlett.2012.7

[6] Feng Y., Guo J.: Biodegradable polydepsipeptides. International Journal of Molecular Sciences, 10, 589-615 (2009).

DOI: $10.3390 /$ ijms 10020589

[7] Feng Y., Behl M., Kelch S., Lendlein A.: Biodegradable multiblock copolymers based on oligodepsipeptides with shape-memory properties. Macromolecular Bioscience, 9, 45-54 (2009).

DOI: 10.1002/mabi.200800199

[8] Feng Y., Lu J., Behl M., Lendlein A.: Degradable depsipeptide-based multiblock copolymers with polyester or polyetherester segments. The International Journal of Artificial Organs, 34, 103-109 (2011).

DOI: $10.5301 / \mathrm{IJAO} .2011 .6402$ 
[9] Bao R., Ding Z., Zhong G., Yang W., Xie B., Yang M.: Deformation-induced morphology evolution during uniaxial stretching of isotactic polypropylene: Effect of temperature. Colloid and Polymer Science, 290, 261274 (2012).

DOI: $10.1007 / \mathrm{s} 00396-011-2550-5$

[10] Jiang Z., Tang Y., Men Y., Enderle H-F., Lilge D., Roth S. V., Gehrke R., Rieger J.: Structural evolution of tensile-deformed high-density polyethylene during annealing: Scanning synchrotron small-angle X-ray scattering study. Macromolecules, 40, 7263-7269 (2007). DOI: $10.1021 / \mathrm{ma} 0627572$

[11] Sarva S. S., Hsieh A. J.: The effect of microstructure on the rate-dependent stress-strain behavior of poly(urethane urea) elastomers. Polymer, 50, 3007-3015 (2009). DOI: $10.1016 /$ j.polymer.2009.04.025

[12] Hu J. L., Ji F. L., Wong Y. W.: Dependency of the shape memory properties of a polyurethane upon thermomechanical cyclic conditions. Polymer International, 54, 600-605 (2005).

DOI: $10.1002 /$ pi.1745
[13] McClung A. J., Tandon G. P., Baur J. W.: Strain rateand temperature-dependent tensile properties of an epoxy-based, thermosetting, shape memory polymer (Veriflex-E). Mechanics of Time-Dependent Materials, 16, 205-221 (2012).

DOI: $10.1007 / \mathrm{s} 11043-011-9148-7$

[14] Azra C., Plummer C. J. G., Månson J-A. E.: Isothermal recovery rates in shape memory polyurethanes. Smart Materials and Structures, 20, 082002/1-082002/10 (2011). DOI: $10.1088 / 0964-1726 / 20 / 8 / 082002$

[15] Scherrer P.: Bestimmung der inneren Struktur und der Größe von Kolloidteilchen mittels Röntgenstrahlen. in 'Kolloidchemie Ein Lehrbuch' (Ed.: Zsigmondy R.) Springer, Berlin, 387-409 (1912). DOI: $10.1007 / 978-3-662-33915-27$

[16] Stribeck N.: X-ray scattering of soft matter. Springer, Berlin (2007). 